\title{
Effect of annealing temperature on the structural and electrical properties of mesoporous $\mathrm{La}_{0.7} \mathrm{Sr}_{0.3} \mathrm{MnO}_{3}$
}

\author{
Chang-Sun PARK, Min-Hee HONG and Hyung-Ho PARK ${ }^{\dagger}$ \\ Department of Materials Science and Engineering, Yonsei University, Seodaemun-Gu, Seoul 120-749, Korea
}

\begin{abstract}
The structural and electrical properties of mesoporous $\mathrm{La}_{0.7} \mathrm{Sr}_{0.3} \mathrm{MnO}_{3}$ (LSMO) films for electrode applications were investigated as a function of annealing temperature. Mesoporous LSMO films were successfully synthesized by using sol-gel and evaporationinduced self-assembly processes. Metal acetates and Brij-S10 were used as the starting material and pore structure-forming template, respectively. With the adoption of mesoporous structure in the LSMO film, the surface area of mesoporous LSMO films was increased up to $165 \%$ with an annealing temperature increase from 350 to $650^{\circ} \mathrm{C}$. The electrical conductivity value of mesoporous LSMO was determined to be $46 \mathrm{~S} / \mathrm{cm}$ at a measurement temperature of $500^{\circ} \mathrm{C}$. This greatly increased the surface area and provided reasonable electrical conductivity, which makes mesoporous LSMO films suitable as electrode materials of micro-solid oxide fuel cell devices.
\end{abstract}

(C2014 The Ceramic Society of Japan. All rights reserved.

Key-words : Mesoporous $\mathrm{La}_{0.7} \mathrm{Sr}_{0.3} \mathrm{MnO}_{3}$, Structural properties, Electrical properties

[Received February 14, 2014; Accepted May 3, 2014]

\section{Introduction}

Today, mobile equipment must meet the requirements of various situations. In order to develop effective mobile equipment, compact and multi-functional devices are being developed. Also, a smooth power supply is vital to the operation of mobile equipment. ${ }^{1)}$ Micro-solid oxide fuel cells ( $\mu$-SOFC) have been widely studied to meet these power requirements. ${ }^{2)} \mu$-SOFCs require a high temperature environment $\left(300\right.$ to $\left.500^{\circ} \mathrm{C}\right)$ to achieve fast ionization for high power generation efficiency. ${ }^{3)}$ To achieve high temperature stability, $\mu$-SOFC uses ceramic electrodes instead of unstable metal electrodes at high temperature because the structural deformation of metal electrodes can occur as hillocks, blisters and agglomeration. ${ }^{4)}$ Several perovskite materials have been studied for use as electrode materials at high temperature. ${ }^{5), 6)}$ Among the perovskite materials, $\mathrm{La}_{0.7} \mathrm{Sr}_{0.3} \mathrm{MnO}_{3}$ (LSMO) has been of interest because this material has good conductivity and thermal stability. ${ }^{7)}$ LSMO is an $\mathrm{ABO}_{3}$-type perovskite crystal and is a chemically and thermally stable oxide. LSMO has excellent electrical conductivity and has been widely studied for applications in many devices. The conduction mechanism of LSMO can be explained in terms of double exchange interaction. ${ }^{8), 9)}$ When the Mn ions have a mixed valence state of $\mathrm{Mn}^{3+}$ and $\mathrm{Mn}^{4+}$, the exchange occurred between $\mathrm{Mn}^{3+}$ and $\mathrm{Mn}^{4+}$. This exchange is a double exchange interaction. From this high temperature stability and relatively high electrical conductivity, applications of LSMO in cathodes of SOFCs have also been studied. ${ }^{10)}$ When LSMO is used as a $\mu$-SOFC cathode, LSMO has the extra advantage of high electrochemical activity for the oxygen reduction reaction. For these reasons, $\mu$-SOFC can show fast ionization, high long-term stability and improved reliability with the LSMO cathode.

Recently, an improvement in surface area of cathode materials

\footnotetext{
$\dagger$ Corresponding author: H.-H. Park; E-mail: hhpark@yonsei. ac.kr

* Preface for this article: Dol http://dx.doi.org/10.2109/jcersj2.122.P8-1
}

has been achieved to maximize the oxygen exchange reaction. ${ }^{11)}$ Nanostructures with high surface area are very diverse and include hollow, mesoporous, aerogel, wire and rod structures. With nanostructures, the surface area of LSMO can be improved, however this can be difficult. In the case of mesoporous structures, pores of 2 to $50 \mathrm{~nm}$ are achieved with regular distributions. ${ }^{12)}$ The mesoporous structure can be synthesized using the evaporation-induced self-assembly (EISA) process. ${ }^{13)}$ EISA means a self-assembly process of surfactants which form micelles by a gradual increase in concentration. The EISA process is simple, easy, and low cost. ${ }^{14)-16)}$ In this study, LSMO mesoporous thin films were prepared by using the EISA process with various annealing temperatures. We analyzed structural and electrical properties to determine the possibility of using mesoporous LSMOs in $\mu$-SOFC.

\section{Experimental}

Mesoporous LSMO films were synthesized on $\mathrm{SiO}_{2} / \mathrm{Si}$ substrates by sol-gel and spin coating processes. In this work, metal acetates $\left[\mathrm{La}\left(\mathrm{CH}_{3} \mathrm{CO}_{2}\right)_{3} \cdot 3 \mathrm{H}_{2} \mathrm{O}\right.$ (Aldrich), $\mathrm{Mn}\left(\mathrm{CH}_{3} \mathrm{CO}_{2}\right)_{2}$ (Aldrich) and $\operatorname{Sr}\left(\mathrm{CH}_{3} \mathrm{CO}_{2}\right)_{2}$ (Aldrich)] were used to synthesize the metal propionate powder. Brij-S10 $\left(\mathrm{C}_{58} \mathrm{H}_{118} \mathrm{O}_{21}\right.$, Aldrich, MW 711), which forms micelle structures, was used as a surfactant. Metal acetates were dissolved in a large excess of propionic acid $\left(\mathrm{C}_{3} \mathrm{H}_{6} \mathrm{O}_{2}\right.$, Duksan $)$ and the liberated acetic acid was distilled to prepare the propionates. The excess propionic acid was separated by centrifugation, followed by precipitation of the carboxylates with acetone $\left(\mathrm{CH}_{3} \mathrm{COCH}_{3}\right.$, Duksan). The product was dried in a dry oven at $50^{\circ} \mathrm{C}$, resulting in dried metal-propionates. We mixed the solution through three steps to prepare the LSMO precursor. The weights of propionates of $\mathrm{La}, \mathrm{Mn}$ and $\mathrm{Sr}$ were adjusted with a composition of LSMO, and weighed propionates were dissolved in propionic acid under stirring for $4 \mathrm{~h}$. Then, the Brij-S10 surfactant was dissolved in n-butyl alcohol $\left[\mathrm{CH}_{3}\left(\mathrm{CH}_{2}\right)_{3} \mathrm{OH}\right.$, Duksan] under stirring for $1 \mathrm{~h}$. Finally, the LSMO precursor was mixed with a surfactant solution and stirred for $30 \mathrm{~min}$. The final product had a composition of LSMO:Brij-S10:propionic acid: 
n-butyl alcohol in a molar ratio of 1:0.014:15:20.

Mesoporous LSMO films were prepared by spin coating onto a $\mathrm{SiO}_{2} / \mathrm{Si}$ substrate through the EISA process. Four different annealing temperatures were chosen, i.e., 350, 450, 550 and $650^{\circ} \mathrm{C}$, and the annealing time was $2 \mathrm{~h}$. X-ray diffraction (XRD: Ultima IV, Rigaku) using $\mathrm{Cu} \mathrm{K} \alpha$ radiation $(\lambda=1.5418 \AA)$ was performed in small-angle ( $2 \theta$ from 0.5 to $\left.5^{\circ}\right)$ and wide-angle $(2 \theta$ from 20 to $60^{\circ}$ ) ranges to study the pore ordering and crystalline structure of mesoporous LSMO films, respectively. The mesostructure of LSMO films was investigated using grazing incidence small angle X-ray scattering (GISAXS) at the $3 \mathrm{C}$ beam line $\left(\lambda=1.24 \AA\right.$ and $\left.\Delta \mathrm{E} / \mathrm{E}=2 \times 10^{-4}\right)$ of the Pohang Light Source (PLS) in the Republic of Korea. The porosity of the mesoporous LSMO thin films was measured using an ellipsometer (Gatan L117C, $632.8 \mathrm{~nm} \mathrm{He}-\mathrm{Ne}$ lasers) and the Lorentz-Lorenz equation. ${ }^{17)}$ Surface area of the LSMO was measured using $\mathrm{N}_{2}$ adsorption desorption analysis (TriStar 3000 V6.05 A). Hall measurement equipment was used to measure the carrier concentration of mesoporous LSMO thin films in a temperature range from 50 to $500^{\circ} \mathrm{C}$ with an interval of $50^{\circ} \mathrm{C}$.

\section{Results and discussion}

In order to confirm the crystalline state of LSMO phases and the pore structure in LSMO mesoporous films after annealing at various temperatures, we carried out small- and wide-angle XRD analysis, and the diffraction patterns are presented in Fig. 1. From Fig. 1(a), the diffraction patterns revealed that a monophase of $\mathrm{La}_{0.7} \mathrm{Sr}_{0.3} \mathrm{MnO}_{3}$ was formed above $550^{\circ} \mathrm{C}$. The $650^{\circ} \mathrm{C}$ annealed sample showed a narrower diffraction peak than the $550^{\circ} \mathrm{C}$-annealed sample due to grain growth. From the diffraction patterns, the grain sizes were calculated to be 9.5 and $21.5 \mathrm{~nm}$ for the $550^{\circ} \mathrm{C}$ - and $650^{\circ} \mathrm{C}$-annealed samples, respectively. This grain growth of the skeletal structure in the LSMO mesoporous structure induces a collapse of the mesoporous structure, as shown in
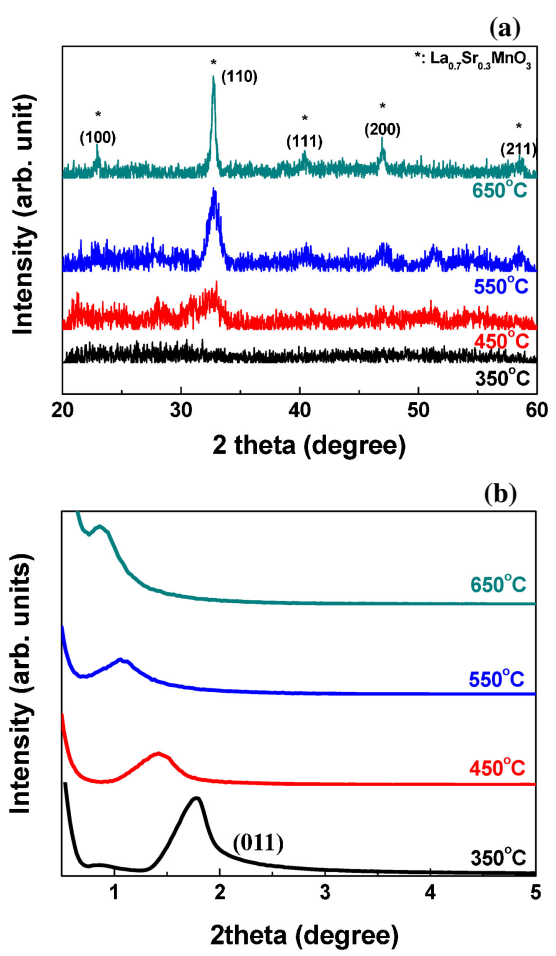

Fig. 1. (a) Wide angle and (b) small angle XRD patterns of mesoporous LSMO films with various annealing temperatures.
Fig. 1(b). ${ }^{18)}$ In small-angle XRD measurement results, diffraction peak intensity was decreased with increased annealing temperature because of a decrease in the ordering of pores in the mesoporous structure from a pore collapse. As the annealing temperature increased, the diffraction peak position moved to small $2 \theta$ angles. The shift in the diffraction peak position corresponds to an increase in the interpore distance. From the diffraction pattern analysis, the interpore distance was increased from 5.7 to 11.5 $\mathrm{nm}$ with increased annealing temperature. This increase in the interpore distance corresponds to a decrease in the porosity resulting from a collapse of mesoporous structure. GISAXS analyses were carried out to clarify the effect of annealing temperature on mesoporous structure, and the results are given in Fig. 2. When an X-ray is scattered at the surface of a sample at a low grazing incidence, an $\mathrm{X}$-ray is emitted due to a change in the surface density. Because the emitted X-ray strikes the twodimensional detector in the horizontal and vertical dimensions, the pore structure can be analyzed in detail. ${ }^{19)}$

As shown in Fig. 2, the GISAXS pattern of the $350^{\circ} \mathrm{C}$-annealed sample shows a weak wing-type shape, and other patterns show a triangular prism-type shape. This wing-type pattern indicates the presence of an ordered pore arrangement in the mesoporous structure. ${ }^{20)} \mathrm{A}$ change in pattern type means a collapse of pore arrangement during the high temperature anneal treatment, but the triangular prism-type pattern corresponds to the remaining pore structure above $450^{\circ} \mathrm{C}$. Previous work showed that a triangular prism-type pattern is observed due to an order-disorder pore arrangement transition. ${ }^{21)}$

$\mathrm{N}_{2}$ absorption of LSMO films was measured to investigate changes in surface area resulting from pore structure change, and the results are shown in Fig. 3(a). With an annealing temperature increase from 350 to $650^{\circ} \mathrm{C}$, the surface area of LSMO films was increased from 27.4 to $45.2 \mathrm{~m}^{2} / \mathrm{g}$. Figure 3 (b) shows the porosity values of mesoporous LSMO films with various annealing temperatures. Unlike the variation in the surface area, the porosity was decreased from 35.4 to $21.8 \%$ with increased annealing temperature due to pore structure change. With Brij-S10, it was reported that pore structure is formed with a body-centered cubic (BCC) or hexagonal close-packed arrangement. ${ }^{22)}$ Supposing the pore structure to be $\mathrm{BCC}$, we calculated the wall thickness and pore size of the pore structure from a common ratio of the wall thickness to pore size of 1:2 using XRD data. ${ }^{23), 24)}$ With the calculated interpore distance from the 011 diffraction peak, the calculated pore sizes of mesoporous LSMO films annealed at 350, 450, 550 and $650^{\circ} \mathrm{C}$ were $3.2,4.1,5.4$ and $6.6 \mathrm{~nm}$, respectively.

A model for pore structural change with increased annealing
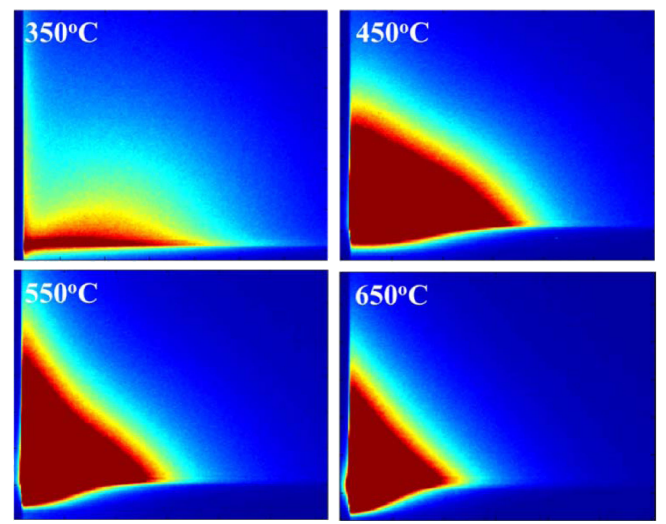

Fig. 2. GISAXS patterns of mesoporous LSMO films with various annealing temperatures. 
(a)

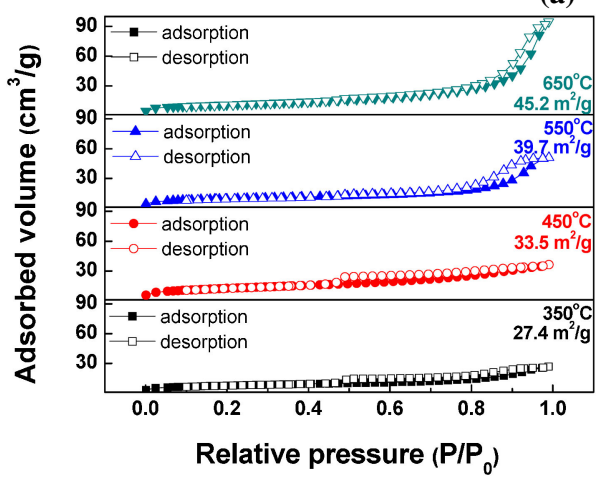

(b)

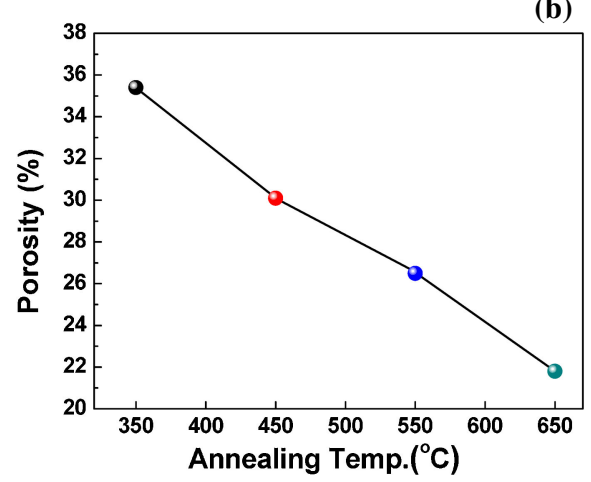

Fig. 3. (a) The $\mathrm{N}_{2}$ sorption isotherms and (b) porosity values of mesoporous LSMO films with various annealing temperatures.

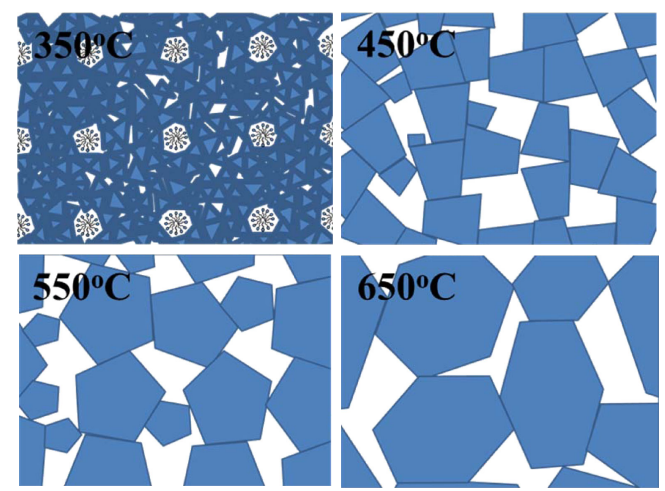

Fig. 4. Schematic model diagram of internal pore structure change of mesoporous LSMO films with various annealing temperatures.

temperature based on grain growth is schematically given in Fig. 4. The grain growth of LSMO should disturb the regular pore arrangement and gradually encroach on the pore structure. Also, with increased annealing temperature, we verified the increase in surface area by pore exposure due to grain growth. In order to confirm the reason for the surface area increase, SEM analysis was carried out and the surface morphology changes of mesoporous and nonporous LSMO films after annealing at various temperatures are shown in Figs. 5(a) and 5(b), respectively. From Figs. 5(a) and 5(b), the surface morphologies of the $350^{\circ} \mathrm{C}$ annealed sample were irregular because of remaining surfactant and organic material from the precursors. In the case of mesoporous LSMO films, surface pores were observed with all the films [Fig. 5(a)]. However, as shown in Fig. 5(b), surface opening from surface crack formation was generated only after annealing at $650^{\circ} \mathrm{C}$. Further, it was confirmed with the XRD
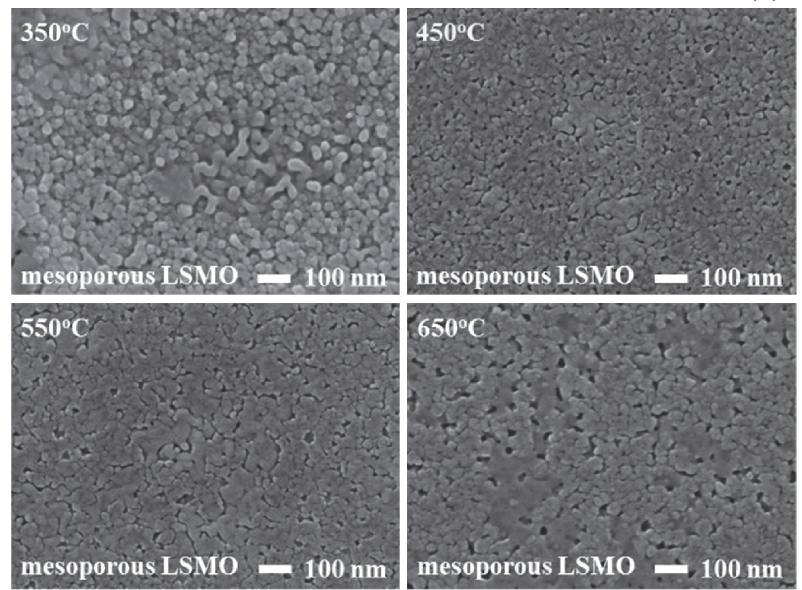

(b)
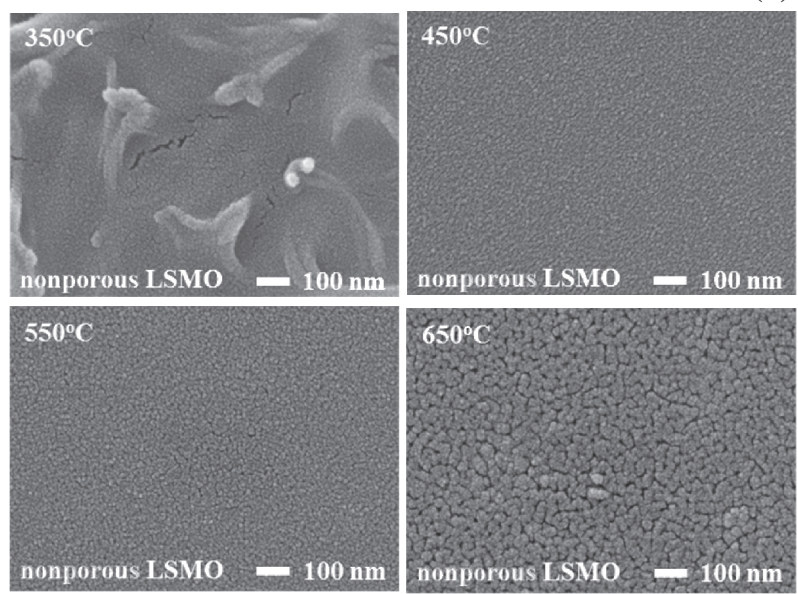

Fig. 5. Surface image of (a) mesoporous and (b) nonporous LSMO films with various annealing temperatures.

results [Fig. 1(a)] that LSMO starts to crystallize above $550^{\circ} \mathrm{C}$. Then, it was concluded that an increase in the surface area of mesoporous films even with a decrease in the porosity was due to an increase in the interior pore connection from particle coarsening as a sintering effect of mesoporous particles. Above $550^{\circ} \mathrm{C}$, a collapse of interior pore structure occurred from grain growth. ${ }^{25)}$ In general, when inducing a pore structure in conducting oxides, the electrical conductivity decreased due to increased scattering of carriers. ${ }^{26)}$ In this study, when increasing the annealing temperature, the surface area was increased but the porosity was decreased by a collapse of interior pores. For this reason, we can expect an increase in the surface area, but with slightly changed electrical conductivity.

In order to confirm the pore structural effect, the electrical properties of the nonporous and mesoporous LSMO films annealed at various temperatures were measured, and the results are given in Fig. 6. From Fig. 6(a), the room temperature resistivity of nonporous and mesoporous LSMO films annealed at $450^{\circ} \mathrm{C}$ were larger than $1 \times 10^{3} \mathrm{ohm} \cdot \mathrm{cm}$. The resistivities of LSMO films showed a decreasing behavior with increasing annealing temperature for both nonporous and mesoporous states due to an enhancement in the crystalline state of the films. The enhanced crystallization was confirmed with wide angle XRD data [Fig. 1(a)] and SEM images (Fig. 5). The absence of crystallinity is a main reason for the high resistivity in the case of the annealed sample at $350^{\circ} \mathrm{C}$. The resistivity decreased as the 
(a)

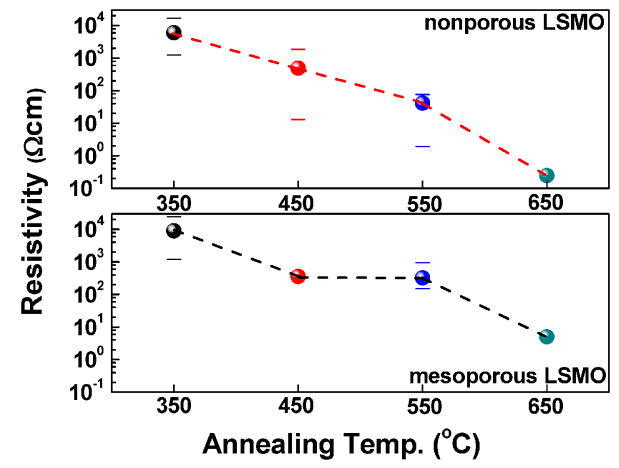

(b)

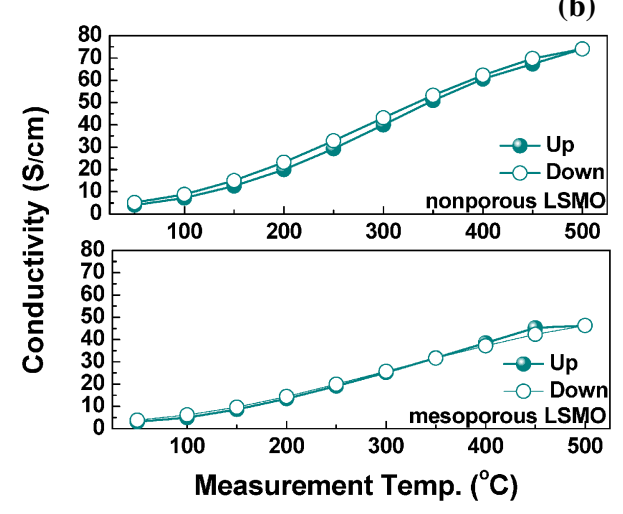

Fig. 6. (a) Electrical resistivity of nonporous and mesoporous LSMO films with various annealing temperatures, and (b) electrical conductivity of $650^{\circ} \mathrm{C}$-annealed nonporous and mesoporous LSMO films at measurement temperatures from 50 to $500^{\circ} \mathrm{C}$.

temperature increased from 550 to $650^{\circ} \mathrm{C}$ due to grain growth. On the other hand, the mesoporous LSMO films showed higher resistivity than nonporous LSMO films due to carrier scattering by pores. However, to confirm the possibility of applying mesoporous LSMO in electrodes, the temperature dependent conductivity of the $650^{\circ} \mathrm{C}$-annealed sample was measured and compared with that of a nonporous LSMO film, as shown in Fig. 6(b). A measurement temperature range from 50 to $500^{\circ} \mathrm{C}$ was chosen because it covered the operating temperature range of $\mu$-SOFC devices. The film showed a semiconductive nature, i.e., increased conductivity with increasing temperature. The electrical conductivity values of nonporous LSMO and mesoporous LSMO were measured to be 74 and $46 \mathrm{~S} / \mathrm{cm}$ at $500^{\circ} \mathrm{C}$, respectively. Even with an applied mesoporous structure, the electrical conductivity was not decreased as expected, but this was accompanied by a significant increase in surface area. It is known that the performance of $\mu$-SOFC is still limited by the cathode polarization resistance. ${ }^{27)}$ The SOFC cathode polarization resistance is expressed as below. ${ }^{27)}$

$$
\begin{aligned}
R_{\text {Cathode }}= & R_{\text {Gas difussion }}+R_{\text {Surface adsorbtion } / \text { diffusion }} \\
& +R_{\text {Charge transfer }}+R_{\text {Ohmic }}
\end{aligned}
$$

In this equation, $R_{\text {Surface adsorbtion/diffusion }}+R_{\text {Charge transfer }}$ can be controlled by the cathode surface area. ${ }^{28)}$ In general, the resistance value was decreased with an increase in cathode surface area. ${ }^{29)}$ In the case of mesoporous structures, the surface area of the LSMO film was increased up to $165 \%$. Although the electrical conductivity was decreased with adoption of mesoporous structure, the value was high enough at the operation temperature. ${ }^{30}$ ) As a result, it can be said that mesoporous structured LSMO films can be applied to $\mu$-SOFC because of the relatively small decrease in the electrical conductivity but highly increased surface area, which induces a reduced $R_{\text {Surface adsorbtion/diffusion }}+R_{\text {Charge transfer }}$

\section{Conclusions}

In this study, a mesoporous LSMO film was successfully synthesized using a metal propionate precursor and a Brij-S10 copolymer surfactant. Thermal treatments lead to the collapse of the porous structure and surface cracks were formed by collapse of the inner pore. High surface area electrode materials were synthesized, i.e., $45.2 \mathrm{~m}^{2} / \mathrm{g}$ for mesoporous LSMO. The electrical conductivity of mesoporous LSMO was $46 \mathrm{~S} / \mathrm{cm}$ near the operating temperature of $\mu$-SOFC. We conclude enhanced reaction area and small change in the electrical conductivity can be obtained through applying a pore structure.

Acknowledgment This work was supported by the National Research Foundation of Korea (NRF) grant funded by the Korea government (MEST) (No. 2012R1A2A2A01011014). This work was supported by the third Stage of Brain Korea 21 Plus Project in 2014. Experiments at PLS were supported in part by MEST and POSTECH.

\section{References}

1) F. Takei, N. F. Cooray, K. Yoshida, H. Yoshida, K. Ebisu, S. Suzuki and N. Sawatari, Fujitsu Sci. Tech. J., 41, 191-200 (2005).

2) W. Lawlor, S. Griesser, G. Buchinger, A. G. Olabi, S. Cordiner and D. Meissner, J. Power Sources, 193, 387-399 (2009).

3) P. C. Su and F. B. Prinz, Electrochem. Commun., 16, 77-79 (2012).

4) P. R. Gadkari, A. P. Warren, R. M. Todi, R. V. Petrova and K. R. Coffey, J. Vac. Sci. Technol., A, 23, 1152-1161 (2005).

5) J. Mizusaki, Solid State Ionics, 52, 79-91 (1992).

6) C.-S. Park and H.-J. Sun, J. Korean Phys. Soc., 57, 994-999 (2010).

7) W. X. Chen, H. W. Nie, W. H. Huang, R. Zheng, H. Y. Tu, Z. Y. Lu and T.-L. Wen, J. Mater. Sci. Lett., 22, 651-653 (2003).

8) J. S. Fang, F.-W. Tsai and T.-S. Chin, Jpn. J. Appl. Phys., 41, 600-605 (2002).

9) C. Zener, Phys. Rev., 82, 403-405 (1951).

10) A. S. Carter, A. Selcuk, R. J. Chater, J. Kajda, J. A. Kilner and B. C. H. Steele, Solid State Ionics, 53, 597-605 (1992).

11) C. Johnson, R. Gemmen and N. Orlovskaya, Compos., Part B Eng., 35, 167-172 (2004).

12) J. Rouquerol, D. Avnir, C. W. Fairbridge, D. H. Everett, J. M. Haynes, N. Pernicone, J. D. F. Ramsay, K. S. W. Sing and K. K. Unger, Pure Appl. Chem., 66, 1739-1758 (1994).

13) Y. Lu, R. Ganguli, C. A. Drewien, M. T. Anderson, C. J. Brinker, W. Gong, Y. Guo, H. Soyez, B. Dunn, M. H. Huang and J. I. Zink, Nature, 389, 364-368 (1997).

14) E. K. Richman, T. Brezesinski and S. H. Tolbert, Nat. Mater., 7, 712-717 (2008).

15) C. J. Brinker, Y. Lu, A. Sellinger and H. Fan, Adv. Mater., 11, 579-585 (1999).

16) D. Grosso, F. Cagnol, G. J. de A. A. Soler-Illia, E. L. Crepaldi, H. Amenitsch, A. Brunet-Bruneau, A. Bourgeois and C. Sanchez, Adv. Funct. Mater, 14, 309-322 (2004).

17) M. R. Baklanov, K. P. Mogilnikov, V. G. Polovinkin and F. N. Dultsev, J. Vac. Sci. Technol., B, 18, 1385-1391 (2000).

18) S. H. Elder, Y. Gao, X. Li, J. Liu, D. E. McCready and C. F. Windisch, Jr., Chem. Mater., 10, 3140-3145 (1998).

19) D. A. Doshi, A. Gibaud, V. Goletto, L. Mengcheng, G. Henry, O. Benjamin, M. H. Sang and C. J. Brinker, J. Am. Chem. Soc., 125, 11646-11655 (2003).

20) E. Lancelle-Beltran, P. Prené, C. Boscher, P. Belleville, P. 
Buvat, S. Lamberti, F. Guillet, C. Boissière, D. Grosso and C. Sanchez, Chem. Mater., 18, 6152-6156 (2006).

21) J. R. Casanova, E. A. Heredia, C. D. Bojorge, H. R. Cánepa, G. Kellermann and A. F. Craievich, Appl. Surf. Sci., 257, 10045-10051 (2011).

22) S. B. Jung and H.-H. Park, Thin Solid Films, 494, 320-342 (2006).

23) T.-J. Ha, H.-H. Park, E. S. Kang, S. Shin and H. H. Cho, J. Colloid Interface Sci., 345, 120-124 (2010).

24) T.-J. Ha, H.-G. Im, S.-J. Yoon, H. W. Jang and H.-H. Park, J. Nanomater, 326472 (2011).
25) T.-J. Ha, M.-H. Hong, C.-S. Park and H.-H. Park, Sens. Actuators, B-Chem., 181, 874-879 (2013).

26) H. Lee, D. Vashaee, D. Z. Wang, Mildred S. Dresselhaus, Z. F. Ren and Gang Chen, J. Appl. Phys., 107, 094308 (2010).

27) A. Samson, M. Sogaard, R. Knibbe and N. Bonanos, J. Electrochem. Soc., 158, B650-B659 (2011).

28) E. D. Wachsman and E. N. Armstrong, ECS Trans., 35, 19551963 (2011).

29) I. Kivi, P. Möller, H. Kurig, S. Kallip, G. Nurk and E. Lust, Electrochem. Commun., 10, 1455-1458 (2008).

30) H. U. Anderson, Solid State Ionics, 52, 33-41 (1992). 